\title{
Prediction of Pharmacokinetics of Antibiotics in Patients with End-Stage Renal Disease
}

\author{
Naoyuki TaJima, ${ }^{* a}$ Satoru Nagashima, ${ }^{c}$ Toshihiko Uematsu, ${ }^{c}$ Hideki ToriI,${ }^{c}$ Masami Tajima, ${ }^{b}$ \\ Akira HishidA, ${ }^{d}$ and Hideo NAGANUMA ${ }^{a}$ \\ ${ }^{a}$ Clinical Pharmacology and Biostatistics Department, and ${ }^{b}$ Drug Metabolism and Pharmacokinetics Research \\ Laboratories, Sankyo Co., Ltd.; 1-2-58 Hiromachi, Shinagawa-ku, Tokyo 140-8710, Japan: ' Shitoro Clinic; 621 \\ Nishikamoecho, Hamamatsu, Shizuoka 432-8067, Japan: and ${ }^{d}$ First Department of Medicine, Hamamatsu University \\ School of Medicine; 1-20-1 Handayama, Hamamatsu, Shizuoka 431-3192, Japan.
}

Received March 10, 2006; accepted April 15, 2006; published online April 21, 2006

A novel and convenient method to predict the pharmacokinetics of several kinds of antibiotic agents in patients with end-stage renal disease (ESRD) was examined based on the in vitro extraction ratios and pharmacokinetic parameters in healthy volunteers. The dializability of 17 antibiotic agents in $4 \%$ human serum albumin solution were determined using a high-performance hemodialytic membrane for clinical use. We assumed that the off-hemodialysis clearance approximated the non-renal clearance, while the on-hemodialysis clearance was considered to be sum of the off-hemodialysis clearance and the hemodialytic clearance. The estimated on- and offhemodialysis clearances were compared with the ones observed in ESRD patients. In order to confirm the method prospectively, an in vivo pharmacokinetic study was performed in dogs with mercury chloride-induced experimental renal failure. The in vitro extraction ratios of $9 \beta$-lactams were broadly ranged from 10.9 to $75.6 \%$ depending on their physicochemical properties. In contrast, those of the other antibiotics were consistent with their chemical classes: $\mathbf{6 0 . 5}-\mathbf{6 3 . 2} \%$ for fluoroquinolone, $48.8-51.1 \%$ for aminoglycoside and $\mathbf{1 8 . 7}-\mathbf{2 5 . 6 \%}$ for glycopeptide. Both the estimated on- and off-hemodialysis clearances of the 17 antibiotics coincided well with the observed values in the literature, regardless of their physicochemical and pharmacokinetic properties. The validity and applicability of this method to three cefems, cefmetazole, cefotaxime and cefoperazone, was prospectively confirmed in the animal study. In conclusion, this new method enables the prediction of the on- and off-hemodialysis clearances of several kinds of antibiotics in ESRD patients from minimal information of their pharmacokinetics in healthy subjects and their in vitro dializability.

Key words prediction; pharmacokinetics; hemodialysis; end-stage renal disease (ESRD); antibiotic

The pharmacokinetics in patients with end-stage renal disease (ESRD) is quite different from that in patients with normal renal function. Numerous approaches are undertaken to appropriately adjust the dosage regimens of renal excretory drugs in ESRD patients because the systemic exposure in this population unexpectedly increases and frequently causes adverse events. In contrast, hemodialysis sometimes results in an inadequate decrease of the plasma drug level from the therapeutic range. ${ }^{1-4)}$ Consequently, pharmacokinetic information for ESRD patients is requisite in the process of new drug development in order to ascertain the effect of renal failure on tolerability and exposure and to determine the dosage regimen. ${ }^{5}$ )

However, the clinical study of ESRD patients has not often been performed due to difficulties with patient enrollment. In such cases, prediction of the pharmacokinetics might be an alternative to clinical studies and provide useful information for optimizing the dosage regimen.

Modeling and simulation have been explored by many scientists, ${ }^{6,7)}$ and recently virtual clinical trials based on pharmacokinetics and pharmacodynamics (PK/PD) modeling and subsequent simulation have been employed for decisionmaking in drug development prior to cost consuming phase III/IV trials. ${ }^{8)}$ In particular, this kind of methodology is informative for the development of antibiotic agents, since there is clear evidence that the pharmacological effect is well correlated to some PK/PD parameters. $\left.{ }^{9}, 10\right)$

Hemodialysis is a physical process that can be described by a mathematical model. ${ }^{3,11)}$ There are many factors affect- ing drug removal during hemodialysis, including molecular weight, lipid and water solubility, surface area, porosity of the dialysis membrane, blood and dialysate flow rates, protein binding and red blood cell partitioning. Even though some methods were previously developed considering these factors, they are complicated for clinical use. Thus, we are trying to develop a simple method based on several assumptions.

Utilization of the chemical structure and pharmacokinetic relationship can be a useful approach for the prediction of pharmacokinetics. ${ }^{6}$ For example, apparent oral clearances in humans could be adequately extrapolated from animal data, while the structural parameters could be evaluated by a multivariate analysis of various drugs selected in view of their structure, molecular weight, partition coefficient, number of hydrogen bond acceptors, pharmacological activities, and pharmacokinetic characteristics. ${ }^{12)}$ Antibiotics are suitable for this approach because they are diverse enough to evaluate the method in terms of various physicochemical and pharmacokinetic properties. $^{13)}$

The purpose of this study was to provide a new method for the prediction of pharmacokinetics in ESRD patients and to confirm its validity and applicability using an experimental renal failure model.

\section{MATERIALS AND METHODS}

Antibiotics and Reagents Cefadroxil, cefazolin, cefoxitin, cefamandole, cefmetazole, cefoperazone, ceftriaxone, 
cefotaxime, enoxacin, ofloxacin and vancomycin were purchased from Sigma-Aldrich Corporation (St. Louis, MO, U.S.A.). Gentamicin and tobramycin were purchased from Calibiochem (San Diego, CA, U.S.A.). Amikacin was purchased from ICN Biochemical Inc. (Aurora, OH, U.S.A.). Teicoplanin was purchased from Fujisawa Pharmaceutical Co., Ltd. (Osaka, Japan). Ciprofloxacin was purchased from Bayer Yakuhin Ltd. (Osaka, Japan). Human serum albumin (HSA) was purchased from Mitsubishi Pharma Corporation (Osaka, Japan). All other reagents used were of guaranteed grade.

In Vitro Hemodialysis Several antibiotics were dissolved in $4 \%$ HSA solution to give a concentration of $100 \mu \mathrm{g} / \mathrm{ml}$. Hemodialysis was performed using an NCU-3 hemodialysis apparatus (Nipro Corporation, Osaka, Japan) with a cellulose triacetate hollow-fiber dialyzer (FB-150G; Nipro Corporation, Osaka, Japan). The dialysate and solution flows were set at $500 \mathrm{ml} / \mathrm{min}$ and $200 \mathrm{ml} / \mathrm{min}$, respectively. The HSA solution was sampled at the outlet of the dialyzer 5,10 , and 15 min after starting the operation. The drug concentrations were measured and the extraction rates $(E)$ were determined as the mean of each time point as follows:

$$
E=\left(C_{\text {inlet }}-C_{\text {outlet }}\right) / C_{\text {inlet }} \times 100(\%)
$$

where $C_{\text {inlet }}$ is the initial concentration and $C_{\text {outlet }}$ is the concentrations collected at the outlet of the dialyzer.

Prediction of Pharmacokinetics in ESRD Patients The total body clearance $\left(C L_{\mathrm{T}}\right)$ is the sum of the renal clearance $\left(C L_{\mathrm{R}}\right)$ and the non-renal clearance $\left(C L_{\mathrm{NR}}\right)$, and $C L_{\mathrm{R}}$ is determined by multiplying $C L_{\mathrm{T}}$ and the renal excretion ratio $(\mathrm{Xu}) . C L_{\mathrm{R}}$ in ESRD patients can be set as zero because their renal function has almost vanished. Thus, the off-hemodialysis clearance $\left(C L_{\text {off }}\right)$, the total body clearance in ESRD patients without hemodialysis, could be equal to $C L_{\mathrm{NR}}$, and could be expressed as follows:

$$
C L_{\text {off }}=C L_{\mathrm{T}} \times(1-\mathrm{Xu})
$$

On the other hand, the hemodialitic clearance of the instrument $\left(C L_{\text {inst }}\right)$ is expressed as follows:

$$
C L_{\text {inst }}=E \times Q \times(1-\mathrm{Hct})
$$

where $E, Q$ and Hct are the in vitro extraction ratio, blood flow rate and hematocrit, respectively. All these values are fixed depending on the drugs, while Hct is usually maintained in most ESRD patients at approximately 0.3 due to the basal treatment of erythropoietin. ${ }^{14)}$

The on-hemodialysis clearance $\left(C L_{\text {on }}\right)$, which is the total body clearance in ESRD patients during hemodialysis, is the sum of $C L_{\text {off }}$ and $C L_{\text {inst }}$, and can be determined using the following equation:

$$
C L_{\text {on }}=C L_{\mathrm{T}} \times(1-\mathrm{Xu})+E \times Q \times(1-\mathrm{Hct})
$$

To evaluate the predictability, the estimated $C L_{\text {off }}$ and $C L_{\text {on }}$ were compared with the observed values in the literature. ${ }^{1,15-35)}$

In Vivo Hemodialysis Study in Dogs Four beagles obtained from Narc (Chiba, Japan) were housed in a temperature- and humidity-controlled room with free access to water. The dogs were handled in accordance with the Guidelines of the Ethics Review Committee for Animal Experimentation of Sankyo Co., Ltd.
A combination of cefmetazole, cefoperazone and cefotaxime $(40 \mathrm{mg} / \mathrm{kg}$ each) was administered intravenously to the dogs. Blood samples were collected at 5, 15, 30, 60, 90 and $120 \mathrm{~min}$ and urine samples were collected for 0 $120 \mathrm{~min}$ after injection. Plasma samples were separated by centrifugation of the blood samples.

After two weeks of withdrawal, $15 \mathrm{mg} / \mathrm{kg}$ of mercury chloride was administered subcutaneously to each dog in order to induce acute renal failure. ${ }^{37)}$ The blood urea nitrogen (BUN) and serum creatinine were monitored as markers of renal function up to $7 \mathrm{~d}$ and the induction of acute renal failure was confirmed. The same combination of antibiotics $(40 \mathrm{mg} / \mathrm{kg}$ each) was administered and blood samples were obtained at $5,10,20,30,45$ and $60 \mathrm{~min}$ after injection. Hemodialysis treatment was started after the last sampling point using an NCU-3 hemodialysis apparatus with an FB-30U dialyzer (Nipro Corporation, Osaka, Japan). The blood and dialysate flows were set at 30 and $500 \mathrm{ml} / \mathrm{min}$, respectively. ${ }^{38,39)}$ Blood samples were collected at 5, 15, 30, 45 and 60 min after the beginning of hemodialysis. The blood samples were centrifuged to separate the plasma and kept at $-20^{\circ} \mathrm{C}$ until analysis.

Pharmacokinetic analysis was performed using WinNonlin (version 4.1, Pharsight, Mountain View, CA, U.S.A.). The plasma concentrations of the normal dogs were fitted to a conventional one-compartment model, and $C L_{\mathrm{T}}$ and distribution volume $(V)$ were determined. $\mathrm{Xu}$ was obtained as a product of the drug concentration and the volume of the bladder urine. The pharmacokinetic parameters of the acute renal failure dogs were computed using the same pharmacokinetic model except the clearance was switched according to the hemodialysis status, namely $C L_{\text {off }}$ and $C L_{\text {on }}$. All data are expressed as the means or mean \pm standard deviations.

Analytical Method Concentrations of gentamicin, amikacin, tobramycin and vancomycin in HSA solution were determined using a TDx/FLx system (Abbott Laboratories, Inc., Abbott Park, IL, U.S.A.). The reagents for analysis were purchased from Abbott Laboratories Inc. (Abbott Park, IL, U.S.A.), except for teicoplanin, which was purchased from Seradyn, Inc. (Indianapolis, IN, U.S.A.). The analyses were precise and accurate, as defined in the operation manual.

The concentrations of other antibiotics in the plasma and HSA solution were determined using an HPLC-UV method. The system consisted of an Alliance 2690 Separations Module equipped with a $486 \mathrm{UV}$ detector (Waters Corporation, Milford, MA, U.S.A.) set at $254 \mathrm{~nm}$ and Xterra RP18, $5 \mu \mathrm{m}$, $4.6 \times 150 \mathrm{~mm}$ (Waters Corporation. Milford, MA, U.S.A.). The mobile phase was a mixture of acetonitrile, distilled water and formic acid and the flow rate was $1.0 \mathrm{ml} / \mathrm{min}$. The lower limit of quantification was $0.1 \mu \mathrm{g} / \mathrm{ml}$, the precision was within $7.9 \%$, and the accuracy ranged between $82.4 \%$ and $106 \%$, which met the criteria for the current bioanalytical methods. ${ }^{40)}$

\section{RESULTS}

Prediction of Pharmacokinetics in ESRD Patients Because the drug concentrations were consistent among sampling points, mean values were used for the extraction ratio (Table 1). The extraction ratios of the $\beta$-lactams broadly ranged from 10.9 to $75.6 \%$, while those of the other antibi- 
Table 1. Extraction Ratios of the Antibiotics Obtained from in Vitro Hemodialysis, and the Observed and Predicted Clearances of ESRD Patients

\begin{tabular}{|c|c|c|c|c|c|c|c|}
\hline \multirow{2}{*}{ Class } & \multirow{2}{*}{ Drugs } & \multirow{2}{*}{$\begin{array}{c}E \\
(\%)\end{array}$} & \multicolumn{2}{|c|}{$C L_{\text {off }}(\mathrm{ml} / \mathrm{min} / \mathrm{kg})$} & \multicolumn{2}{|c|}{$C L_{\text {on }}(\mathrm{ml} / \mathrm{min} / \mathrm{kg})$} & \multirow{2}{*}{ Reference } \\
\hline & & & Observed & Predicted & Observed & Predicted & \\
\hline \multirow[t]{9}{*}{$\beta$-Lactams } & Cefadroxil & 72.1 & 0.20 & 0.17 & 2.09 & 1.73 & 15,16 \\
\hline & Cefazolin & 21.7 & 0.05 & 0.10 & 0.31 & 0.53 & 17 \\
\hline & Cefoxitin & 58.7 & 0.20 & 0.58 & 1.31 & 1.75 & 18,19 \\
\hline & Cefamandole & 19.6 & 0.27 & 1.31 & 0.70 & 1.70 & 15,20 \\
\hline & Cefmetazole & 48.2 & 0.10 & 0.26 & 1.23 & 1.22 & 15,21 \\
\hline & Cefoperazone & 26.3 & 1.07 & 0.82 & 1.94 & 1.35 & 15,22 \\
\hline & Ceftriaxone & 10.9 & 0.19 & 0.12 & 0.19 & 0.34 & 23,24 \\
\hline & Cefotaxime & 62.4 & 1.32 & 1.84 & 2.53 & 3.09 & 15,25 \\
\hline & Panipenem & 75.6 & 0.81 & 2.13 & 2.65 & 3.64 & 26,27 \\
\hline \multirow[t]{3}{*}{ Quinolones } & Ciprofloxacin & 60.5 & 3.67 & 2.76 & 5.91 & 3.97 & 15,28 \\
\hline & Enoxacin & 61.2 & 0.99 & 2.72 & 1.72 & 3.94 & 15,29 \\
\hline & Ofloxacin & 63.2 & 0.70 & 0.92 & 1.38 & 2.18 & 15,30 \\
\hline \multirow[t]{3}{*}{ Aminoglycosides } & Gentamicin & 48.8 & 0.07 & 0.23 & 0.97 & 1.21 & 1,31 \\
\hline & Tobramycin & 51.1 & 0.06 & 0.22 & 0.91 & 1.24 & 1,32 \\
\hline & Amikacin & 48.8 & 0.20 & 0.16 & 0.62 & 1.14 & 1,33 \\
\hline \multirow[t]{2}{*}{ Glycopeptides } & Vancomycin & 25.6 & 0.10 & 0.12 & 0.96 & 0.63 & 1,34 \\
\hline & Teicoplanin & 18.7 & 0.11 & 0.14 & 0.66 & 0.51 & 35,36 \\
\hline
\end{tabular}

$E$ : Extraction ratio represented as the mean of time points, $C L_{\text {off }}$ : total body clearance in ESRD patients without hemodialysis, $C L_{\text {on }}$ : total body clearance in ESRD patients during hemodialysis.

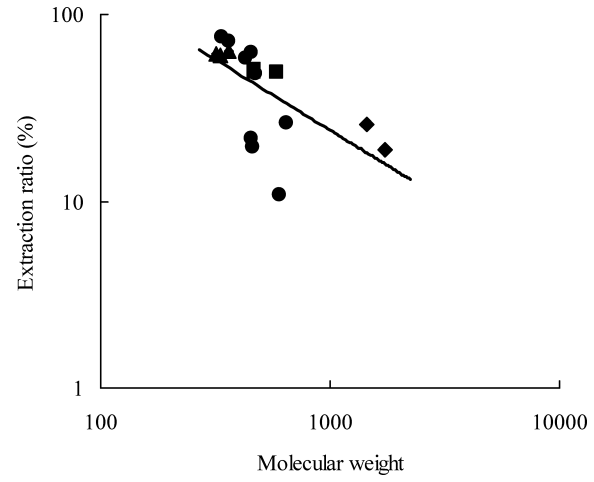

Fig. 1. The Relationship between the Molecular Weight and in Vitro Extraction Ratio for $\beta$-Lactams (), Quinolones $(\boldsymbol{\Delta})$, Aminoglycoside (ם) and Glycopeptides $(\bullet$

The solid line represents the regression curve. $E=4400 \times \mathrm{MW}^{0.754}(R=0.62)$

otics were almost consistent with their chemical class: $60.5-63.2 \%$ for fluoroquinolone, $48.8-51.1 \%$ for aminoglycoside and $18.7-25.6 \%$ for glycopeptide. The relationship between the extraction ratios and molecular weight is shown in Fig. 1. The extraction ratio was loosely correlated with the molecular weight in the HSA solution.

The predicted and observed values of $C L_{\text {off }}$ and $C L_{\text {on }}$ are also shown in Table 1 and the relationships are shown in Fig. 3 . The predicted values coincided with the observed values and no bias was noted in the chemical class of antibiotics for both $C L_{\text {off }}$ and $C L_{\text {on }}$.

In Vivo Hemodialysis Study in Renal Failure Dogs The biochemical parameters before and after the treatment with mercury chloride are shown in Table 2. BUN and serum creatinine were increased and creatinine clearance was decreased after administration of mercury chloride, and these values were equivalent to those in dogs with severe acute renal failure. ${ }^{41)}$

Typical plasma concentrations of cefmetazole, cefotaxime and cefoperazone in a dog before and after induction of acute renal failure are shown in Fig. 3. In the acute renal failure
Table 2. Demographic and Physiopathological Parameters in Normal and Acute Renal Failure Dogs

\begin{tabular}{lcc}
\hline \hline & Normal & Acute renal failure \\
\hline Body weight $(\mathrm{kg})$ & $12.1(0.6)$ & $11.6(0.6)$ \\
BUN $(\mathrm{mg} / \mathrm{dl})$ & $14.6(2.2)$ & $156.9(113)$ \\
Serum creatinine $(\mathrm{mg} / \mathrm{dl})$ & $0.7(0.1)$ & $6.5(5.0)$ \\
Creatinine clearance $(\mathrm{ml} / \mathrm{min})$ & $46.2(24.6)$ & $4.6(5.0)$
\end{tabular}

Data represents mean (SD) of 4 dogs. Acute renal failure was induced by the subcutaneous administration of $15 \mathrm{mg} / \mathrm{kg}$ of mercury chloride.

dogs, the plasma concentration decreased more slowly than in normal dogs, whereas fast elimination was found during hemodialysis treatment. The pharmacokinetic parameters of cefmetazole, cefoperazone and cefotaxime after intravenous administration are summarized in Table 3. $C L_{\text {off }}$ was reduced from $C L_{\mathrm{T}}$, which was derived from the reduction of renal function with acute renal failure, and $C L_{\text {on }}$ was increased from $C L_{\text {off }}$ due to hemodialysis. The predicted and observed values were comparable but slightly different in cefoperazone. The distribution volume was consistent before and after the induction of acute renal failure.

\section{DISCUSSION}

PK/PD modeling and subsequent simulation are powerful tools to anticipate the efficacy and safety of drugs and, consequently, to accelerate new drug development by optimizing the trial design. ${ }^{8)}$ As pharmacokinetics is a reliable determinant, its adequate use by prediction will provide an alternative method to optimize the dosage regimen in a special population such as patients with renal impairment. One other methodology of prediction is based on allometric scaling, which focuses on the relationship between body weight and pharmacokinetic parameters in the several animal species. ${ }^{6}$ However, this empirical approach cannot be applied to all drugs. ${ }^{42)}$ Another approach is to examine the structure-pharmacokinetic behavior relationship to extrapolate any specific 

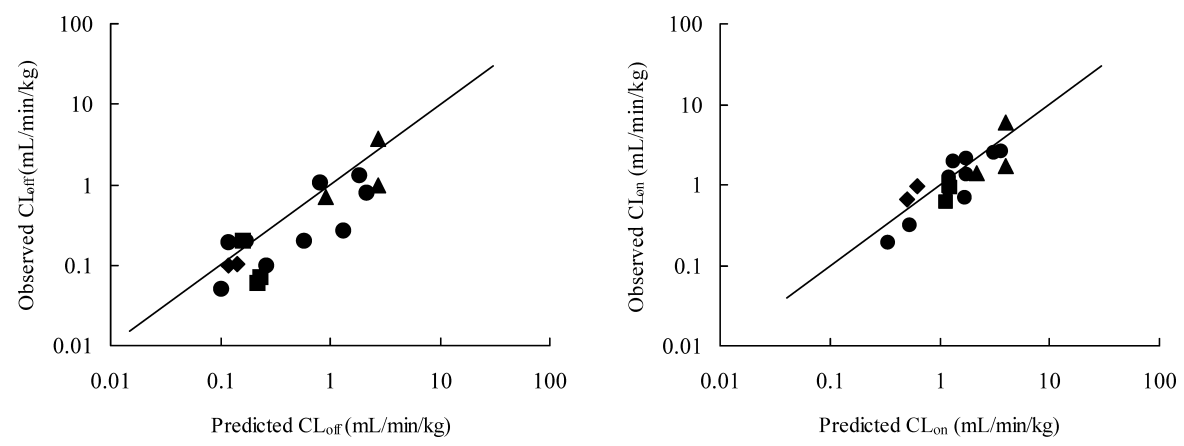

Fig. 2. The Relationship between the Predicted and Observed Values of $C L_{\text {off }}$ (Left) and $C L_{\text {on }}$ Clearance (Right) for $\beta$-Lactams $(\bullet)$, Quinolones $(\mathbf{\Lambda})$, Aminoglycoside ( $\mathbf{\square})$ and Glycopeptides $(\bullet)$ in Humans

The predicted values were obtained from the clearance of healthy volunteers in a previous study and the in vitro extraction ratio. The observed values are previously reported values. $C L_{\text {off }}$ : total body clearance in ESRD patients without hemodialysis, $C L_{\text {on }}$ : total body clearance in ESRD patients during hemodialysis. The solid line represents that of unity.
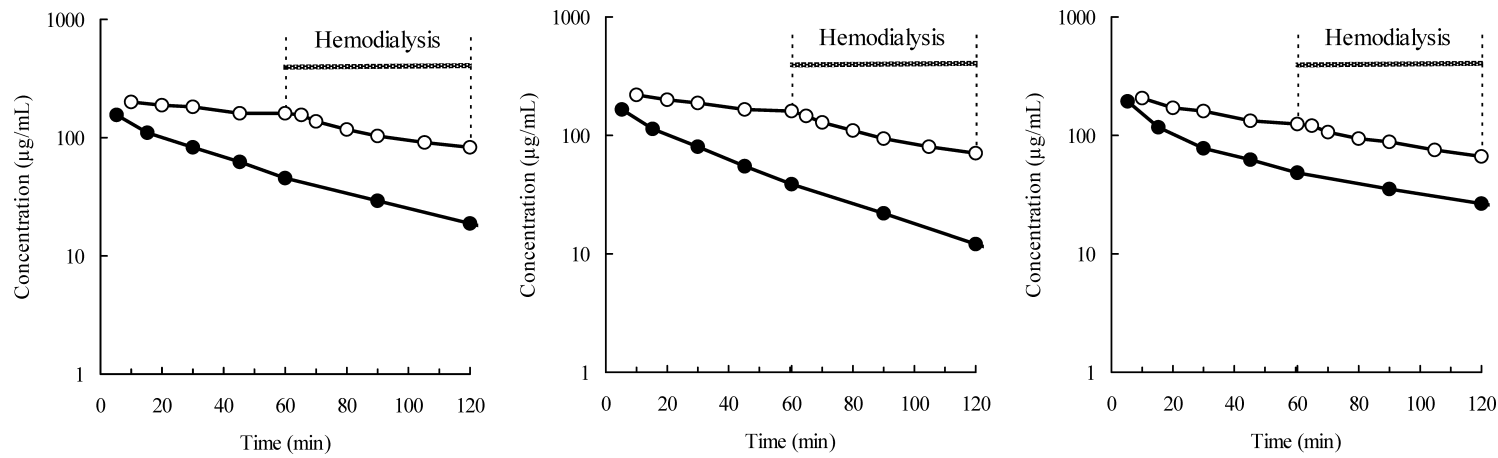

Fig. 3. Plasma Concentrations of Cefmetazole (Left), Cefotaxime (Center) and Cefoperazone (Right) in a Typical Dog

A cocktail of cefmetazole, cefotaxime and cefoperazone $(40 \mathrm{mg} / \mathrm{kg}$, each) was administered intravenously before and after induction of acute renal failure. Hemodialysis was performed $60 \mathrm{~min}$ after the administration of drugs in acute renal failure dogs. Closed and open circles represent the plasma concentrations before and after induction of acute renal failure, respectively.

Table 3. Pharmacokinetic Parameters after the Intravenous Administration of Cefmetazole, Ceftriaxone and Cefoperazone to Normal and Acute Renal Failure Dogs

\begin{tabular}{|c|c|c|c|c|c|c|c|c|c|}
\hline \multirow[b]{2}{*}{ Drugs } & \multicolumn{3}{|c|}{ Normal } & \multicolumn{3}{|c|}{ Acute renal failure } & \multirow[b]{2}{*}{$\begin{array}{c}E \\
(\%)\end{array}$} & \multicolumn{2}{|c|}{ Predicted } \\
\hline & $\begin{array}{c}C L_{\mathrm{T}} \\
(\mathrm{ml} / \mathrm{min})\end{array}$ & $\begin{array}{l}V \\
\text { (1) }\end{array}$ & $\begin{array}{l}\mathrm{Xu} \\
(\%)\end{array}$ & $\begin{array}{c}C L_{\mathrm{off}} \\
(\mathrm{ml} / \mathrm{min})\end{array}$ & $\begin{array}{c}C L_{\text {on }} \\
(\mathrm{ml} / \mathrm{min})\end{array}$ & $\begin{array}{l}V \\
\text { (1) }\end{array}$ & & $\begin{array}{c}C L_{\text {off }} \\
(\mathrm{ml} / \mathrm{min})\end{array}$ & $\begin{array}{c}C L_{\text {on }} \\
(\mathrm{ml} / \mathrm{min})\end{array}$ \\
\hline Cefmetazole & $\begin{array}{l}53.1 \\
(7.7)\end{array}$ & $\begin{array}{c}2.06 \\
(0.29)\end{array}$ & $\begin{array}{c}69.7 \\
(26.5)\end{array}$ & $\begin{array}{c}10.3 \\
(15.5)\end{array}$ & $\begin{array}{c}22.3 \\
(12.4)\end{array}$ & $\begin{array}{c}2.29 \\
(0.77)\end{array}$ & 63.0 & $\begin{array}{c}14.7 \\
(12.4)\end{array}$ & $\begin{array}{c}26.0 \\
(12.4)\end{array}$ \\
\hline Cefoperazone & $\begin{array}{c}39.9 \\
(11.3)\end{array}$ & $\begin{array}{c}1.48 \\
(0.30)\end{array}$ & $\begin{array}{c}50.1 \\
(10.1)\end{array}$ & $\begin{array}{l}11.9 \\
(9.6)\end{array}$ & $\begin{array}{l}18.8 \\
(7.5)\end{array}$ & $\begin{array}{c}1.59 \\
(0.72)\end{array}$ & 66.0 & $\begin{array}{l}19.7 \\
(5.7)\end{array}$ & $\begin{array}{l}31.6 \\
(5.7)\end{array}$ \\
\hline Cefotaxime & $\begin{array}{c}41.2 \\
(29.1)\end{array}$ & $\begin{array}{c}2.18 \\
(0.51)\end{array}$ & $\begin{array}{c}53.6 \\
(22.8)\end{array}$ & $\begin{array}{c}19.4 \\
(21.1)\end{array}$ & $\begin{array}{c}33.5 \\
(16.9)\end{array}$ & $\begin{array}{c}2.50 \\
(1.28)\end{array}$ & 84.5 & $\begin{array}{c}15.2 \\
(12.4)\end{array}$ & $\begin{array}{c}30.4 \\
(12.4)\end{array}$ \\
\hline
\end{tabular}

A cocktail of cefmetazole, cefotaxime and cefoperazone $\left(40 \mathrm{mg} / \mathrm{kg}\right.$, each) was administered intravenously to 4 dogs. Data represents the mean (SD) of 4 dogs. $C L_{\mathrm{T}}$ : total body clearance in normal dogs, $V$ : distribution volume in normal dogs, Xu: urinary excretion ratio in normal dogs, $C L_{\text {off }}$ total body clearance in acute renal failure dogs without hemodialysis, $C L_{\mathrm{on}}$ : total body clearance in acute renal failure dogs during hemodialysis, $E$ : in vitro extraction ratio.

parameters of interest for a variety of different drugs, and this method is considered to be more adequate. ${ }^{12)}$

In this study, we assumed that the off-hemodialysis clearance approximated the non-renal clearance, while the on-hemodialysis clearance was considered to be the sum of the offhemodialysis clearance and the hemodialytic clearance. The prediction of the pharmacokinetics in ESRD patients was evaluated based on allometry using 17 antibiotics. We previously demonstrated this idea for one carbapenem antibiotic, panipenem. ${ }^{27)}$ However, it was not known if this approach would be applicable to other drugs. The 17 antibiotics, which were categorized into 4 different chemical classes, namely, $\beta$-lactam, fluoroquinolone, aminoglycoside and glycopeptide, must be varied enough to demonstrate the applicability of the method to other drugs in view of both physicochemical and pharmacokinetic properties, such as the molecular weight and ionic form for the former, and the total body clearance and renal excretion ratio for the latter. As shown in Table 1 and Fig. 2, $C L_{\text {on }}$ of most drugs were estimated within the range from half to double of the expected values, suggesting that this method would be applicable to a variety of drugs including most of the antibiotic agents used in this study. Although the precise reasons for the poor predictability of cefamandole and enoxacin are unknown, it might be too sim- 
plify to predict $C L_{\text {on }}$ and/or $C L_{\text {off }}$ by this method.

A prospective study is an effective approach to test the predictability of a method, and the result could be extrapolated to humans since renal disease models in experimental animals reflect human diseases and pharmacokinetics. ${ }^{43)}$ As shown in Table 2, the clearances in acute renal failure dogs could be estimated to some extent from the pharmacokinetic parameters obtained from the dogs before induction along with the in vitro extraction ratio.

As shown in Table 1 and Fig. 1, the in vitro extraction ratios ranged broadly reflecting the diversity of molecular weight and protein biding ratio. The extraction ratios were determined mainly by the molecular weight, and the variety of extraction ratios found in $\beta$-lactams would be a consequence of broad protein binding ratios (4-89\%).

In the case of drugs which are mostly excreted in the urine, the term of $(1-\mathrm{Xu})$ is assigned value of zero and thus Eq. (3) is reduced to:

$$
C L_{\text {on }}=E \times Q \times(1-\mathrm{Hct})
$$

This means that $C L_{\text {on }}$ can be fixed without any in vivo $\mathrm{PK}$ information. For example, $C L_{\text {on }}$ of cefmetazole, one of the drugs excreted mostly in urine, could be estimated close to the observed value. On the other hand, the prediction of drugs with lower renal recovery could be easily affected by the remaining non-renal elimination function. $C L_{\text {off }}$ and $C L_{\text {on }}$ might be overestimated due to the reduction of the cytochrome P450 content found in a chronic renal failure model of rats. ${ }^{44}$ )

A high performance dialyzer, which could remove lowmolecular-weight proteins, namely $\beta_{2}$-myoglobin, was used in this study, while most of the observed $C L_{\text {on }}$ was determined with a conventional dialyzer. The $C L_{\text {on }}$ of aminoglycoside, which have molecular weights of more than 1000 , were slightly overestimated since conventional dialyzers were used. However, the $C L_{\text {on }}$ of glycopeptide were consistent to observed values because of the usage of high performance dialyzers. Recently, various kinds of new membranes, e.g. polysulfone, have been developed, ${ }^{45)}$ and for more accurate estimation, the in vitro extraction ratio should be determined using such dialyzers.

Differences have been noted in pharmacokinetic parameters other than the systemic clearance between healthy volunteers and ESRD patients. ${ }^{1,2)}$ Although the distribution volumes of most drugs rise slightly because of water retention, these discrepancies were considerably smaller than the total volume of body fluid and as a result the influence of the pharmacokinetics would be limited. ${ }^{4)}$ A difference was also found in the protein binding due to the reduction of net protein content and accumulation of various kinds of uremic toxins in ESRD patients. Because drugs bound to protein cannot permeate hemodialytic membranes, the free drug concentration is important, in particular, for high protein binding drugs. In order to achieve a more accurate estimation in this situation, the extraction ratio should be adjusted in terms of the protein binding ratio.

In order to maintain the consistent efficacy of a drug, supplemental dosing during or after hemodialysis is sometimes required for ESRD patients. The drugs administered after hemodialysis to keep its concentration within the therapeutic range have low $C L_{\text {off }}$ and high $C L_{\text {on }}$. If both clearances can be estimated properly, we can determine the necessity of supplemental dosing. Thus, prediction is useful in terms of supplemental dosing.

In conclusion, the on- and off-hemodialysis clearance in ESRD patients could be predicted from the pharmacokinetic parameters in healthy subjects and the in vitro extraction ratio of the hemodialysis apparatus. This method was simple and useful for optimizing the dosage regimen. As well, this method was considered to be applicable to various kinds of drugs with a variety of physicochemical and pharmacokinetic characteristics.

\section{REFERENCES}

1) St Peter W. L., Redic-Kill K. A., Halstenson C. E., Clin. Pharmacokinet., 22, 169-210 (1992).

2) Lee C. S., Marbury T. C., Clin. Pharmacokinet., 9, 42-66 (1984).

3) Gibson T. B., Nelson H. A., Clin. Pharmacokinet., 2, 403-426 (1977).

4) Livornese L. L., Jr., Slavin D., Gilbert B., Robbins P., Santoro J., Infect. Dis. Clin. North. Am., 18, 551-579 (2004).

5) Food and Drug Administration, "Guidance for Industry. Pharmacokinetics in Patients with Impaired Renal Function-Study Design, Data Analysis, and Impact on Dosing and Labeling," 1998.

6) Boxenbaum H., J. Pharmacokinet. Biopharm., 10, 201-227 (1982).

7) Bischoff K. B., Dedrick R. L., J. Pharm. Sci., 57, 1346-1351 (1968).

8) Chien J. Y., Friedrich S., Heathman M. A., de Alwis D. P., Sinha V., AAPS J., 7, E544-559 (2005).

9) Craig W. A., Clin. Infect. Dis., 26, 1-10 (1998).

10) Bhavnani S. M., Hammel J. P., Cirincione B. B., Wikler M. A., Ambrose P. G., Antimicrob. Agents Chemother, 49, 3944-3947 (2005).

11) Mac-Kay M. V., Sanchez Burson J., Martinez-Lanao J., DominguezGil A., Clin. Pharmacokinet., 25, 243-257 (1993).

12) Wajima T., Fukumura K., Yano Y., Oguma T., J. Pharm. Sci., 92, $2427-2440$ (2003).

13) Sawada Y., Hanano M., Sugiyama Y., Iga T., J. Pharmacokinet. Biopharm., 12, 241-261 (1984).

14) Frankenfield D., Johnson C. A., Wish J. B., Rocco M. V., Madre F., Owen W. F., Kidney Int., 57, 578-589 (2000).

15) Hardman J. G., Limbird L. E., Gilman A. G., "Goodman and Gilman's the Pharmacological Basis of Therapeutics," 10th ed., McGraw-Hill, New York, 2001.

16) Marino E. L., Domingnez-Gil A., Tabernero J. M., Rubio F., Int. J. Pharmaceut., 9, 263-272 (1981).

17) Leroy A., Canonne M. A., Fillastre J. P., Humbert G., Curr. Ther. Res. Clin. Exp., 16, 878-889 (1974).

18) Garcia M. J., Dominguez-Gil A., Tabernero J. M., Sanchez Tomero J. A., Eur. J. Clin. Pharmacol., 16, 119-124 (1979).

19) Garcia M. J., Dominguez-Gil A., Tabernero J. M., Bondia R. A., Int. J. Clin. Pharmacol. Biopharm., 17, 366-370 (1979).

20) Campillo J. A., Lanao J. M., Dominguez-Gil A., Tabernero J. M., Rubio F., Int. J. Clin. Pharmacol. Biopharm., 17, 416-420 (1979).

21) Halstenson C. E., Guay D. R., Opsahl J. A., Hirata C. A., Olanoff L. S., Novak E., Ko H., Cathcart K. S., Matzke G. R., Antimicrob. Agents Chemother., 34, 519-523 (1990).

22) Spyker D. A., Richmond J. D., Scheld W. M., Bolton W. K., Am. J. Nephrol., 5, 355-360 (1985).

23) Patel I. H., Chen S., Parsonnet M., Hackman M. R., Brooks M. A., Konikoff J., Kaplan S. A., Antimicrob. Agents Chemother, 20, 634 641 (1981).

24) Cohen D., Appel G. B., Scully B., Neu H. C., Antimicrob. Agents Chemother, 24, 529-532 (1983).

25) Hasegawa K., Chemotherapy, 32, 29-37 (1984).

26) Nakashima M., Uematsu T., Kanamaru M., Tajima M., Naganuma H., Hisaoka M., Kawahara Y., Takahagi H., Chemotherapy, 39 (Suppl. 3), $242-264$ (1991).

27) Ohashi N., Uematsu T., Nagashima S., Kanamaru M., Tajima N., Togawa A., Hishida A., J. Infect. Chemother, 11, 24-31 (2005).

28) Boelaert J., Valcke Y., Schurgers M., Daneels R., Rosseneu M., Rosseel M. T., Bogaert M. G., J. Antimicrob. Chemother, 16, 87-93 (1985). 
29) Van der Auwera P., Stolear J. C., George B., Dudley M. N., Antimicrob. Agents Chemother, 34, 1491-1497 (1990).

30) Fillastre J. P., Leroy A., Humbert G., Antimicrob. Agents Chemother, 31, 156-160 (1987)

31) Danish M., Schultz R., Jusko W. J., Antimicrob. Agents Chemother, 6, $841-847$ (1974)

32) Halstenson C. E., Berkseth R. O., Mann H. J., Matzke G. R., Int. J. Clin. Pharmacol. Ther., 25, 50-55 (1987).

33) Regeur L., Colding H., Jensen H., Kampmann J. P., Antimicrob. Agents Chemother., 11, 214-218 (1977).

34) Gonzalez-Martin G., Acuna V., Perez C., Labarca J., Guevara A., Tagle R., Int. J. Clin. Pharmacol. Ther, 34, 71-75 (1996).

35) Bonati M., Traina G. L., Villa G., Salvadeo A., Gentile M. G., Fellin G., Rosina R., Cavenaghi L., Buniva G., Clin. Pharmacokinet., 12, 292-301 (1987)

36) Thalhammer F., Rosenkranz A. R., Burgmann H., Graninger W., Hollenstein U., Schenk P., Thalhammer-Scherrer R., Traindl O., Horl W.
H., Breyer S., Wien. Klin. Wochenschr., 109, 362-365 (1997).

37) Olbricht C. H., Contrib. Nephrol., 19, 110-123 (1980).

38) Ash S. R., Thornhill J. A., Dhein C. R., Rebar A. H., Clin. Exp. Dial Apheresis, 6, 25-44 (1982).

39) DiBartola S. P., Chew D. J., Tarr M. J., Sams R. A., J. Am. Vet. Med. Assoc., 186, 1323-1326 (1985).

40) Karnes H. T., Shiu G., Shah V. P., Pharm. Res., 8, 421-426 (1991).

41) Flamenbaum W., McNeil J. S., Kotchen T. A., Saladino A. J., Circ. Res., 31, 682-698 (1972).

42) Mahmood I., J. Pharm. Sci., 88, 1101-1106 (1999).

43) Tajima N., Soma M., Ishizuka H., Naganuma H., Biol. Pharm. Bull., 28, 2170-2172 (2005)

44) Pichette V., Leblond F. A., Curr. Drug Metab., 4, 91-103 (2003).

45) Brendolan A., Nalesso F., Fortunato A., Crepaldi C., De Cal M., Cazzavillan S., Cruz D., Techawathanawanna N., Ronco C., Int. J. Artif. Organs, 28, 966-975 (2005). 